\title{
COVID-19 Pandemic in Turkey and Kerala, India: Some Observations
}

\section{Seval Akgun $\mathrm{H}^{1 *}$ and Rajasekharan $\mathrm{NK}^{2}$}

${ }^{1}$ Department of Public Health, Baskent University, Ankara, Turkey

${ }^{2}$ Global Institute of Public Health and Santhigiri Research Foundation, India

*Corresponding author: H Seval Akgun, MD, PhD, Professor of Public Health and Medicine, Department of Public Health, Chief Quality Officer, Baskent University Hospitals Network, Ankara, Turkey, Email: sevalak2007@gmail.com

\section{Review Article \\ Volume 4 Issue 2}

Received Date: August 01, 2020

Published Date: September 10, 2020

DOI: $10.23880 /$ phoa-16000159

\section{Abstract}

There is still lack of clarity regarding the effectiveness of various control measures in containing the COVID-19 pandemic. The experiences from different countries or contexts are diverse. For instance in Kerala state of India, the dispersed settlement patterns could have played an important role as against the nucleated, semi-compact or compact patterns elsewhere in the country including the West. The importance of surveillance, good quality quarantine, testing strategies, uninterrupted treatment services, community participation, proactive care of elderly and people with comorbidity and educational and social mobilisation of behavioural change etc. have also been pointed out as factors which contributed to effective management and control of COVID-19 in Kerala. But such optimism did not last long and the virus had an upper hand despite all these claims. After the one single case on 30 January, it soon hit the peak with super spread and community spread reported in some areas. Turkey is one of the few countries in the world which effectively handled the COVID-19 virus largely due to a scientific approach with rigorous testing. What is observed regarding the number of active cases in Turkey is a peak sometime around the middle of April and then a gradual flattening. The success in Turkey could also be attributed to strict enforcement of Standard protocols. Like many other countries, strict quarantine was also enforced. Turks coming from abroad were quarantined at guest houses for 14 days (for those with no clinical signs), and at designated hospitals in each province (for those with clinical symptoms) till June. Standard protocols such as restrictions on meetings, gatherings and travel were followed.

The Country also adopted a fast track mechanism to procure medical supplies, test kits, PPEs, thermal scanners, and other needed diagnostic and curative commodities and distribute it to all possible sites.

There is no doubt that the pandemic has already led to devastating social, economic and political effects that will leave deep and longstanding scars. In the longer term, we should look at ways to better prevent and manage such crises and ensure that the world makes full use of what we will learn from this one. This is the reason why there is a need to examine country case studies to understand patterns especially similarities and differences. But an on-going epidemiological assessment based on data is extremely important to strengthen the fight against the pandemic. This is extremely useful for developing an integrated global response as an investment for our future.

Keywords: COVID-19; Diagnostic; SARS; Vaccine 
Public Health Open Access

\section{Introduction}

The world is still examining possibilities of elimination of the COVID-19 virus and there are many of them. One of the important country-specific actions is discovering a vaccine against the virus. It is also important to examine the infection trends and the actions of countries with respect to various measures in dealing with the pandemic in order to so that effective preventive strategies can be evolved. In this paper, we attempt to present two cases which have been hailed as success stories. One of the most severe pandemics which struck the world in the $20^{\text {th }}$ century was the 1918 Influenza infections which affected many countries and killed millions [1]. Although, called Spanish Flu, this was found to be due to a misunderstanding and it was also thought or may be another assumption that the virus originated in France, China and Britain. Scientists yet could not find the complete details of the strain or why it was so lethal or its country of origin. The West Nile virus epidemic is another milestone. The virus was first identified in 1937 in Uganda. It struck United States in the summer of 1999 in New York. Researchers assume that the virus is spread when a mosquito bites an infected bird and then bites a person [2]. When mosquitos multiply during late August to early September many people are infected and during cold weather the cases disappear. The most interesting feature of this virus infection is that most people do not exhibit any symptoms.

Coronaviruses are a large family of viruses that are known to cause illness ranging from the common cold to more severe diseases such as Middle East Respiratory Syndrome (MERS) and Severe Acute Respiratory Syndrome (SARS). 2019-novel coronavirus (COVID-19) was identified in Wuhan, China. This is a new coronavirus that has not been previously identified in humans. It started from a local seafood market, known to sell live and freshly slaughtered hunted animals such as Bat, Snake and Pangolins. Covid-19 has led to an unprecedented global pandemic affecting persons of all ages. The severe respiratory disease can occur in adults, particularly the elderly and those with underlying health conditions. Most people are being infected from other people. It probably spreads the same way as colds and fluthrough droplets which are created when we talk, cough and sneeze. Some people have been infected following contact with an infected person with minimal or no symptoms.

This paper tries to present two cases from different contexts ie. Kerala in India and Turkey. Both cases have been mentioned as success stories with respect to the control of COVID-19 infection. It tries to present through reviews the epidemiological situation after the initial period of experience in infection control.

\section{COVID-19 in Kerala}

COVID-19 has affected different countries differently based on the context, ecological conditions and even settlement patterns. The role of contacts in spreading the virus is significant. The effectiveness of control measures also played a role in containing the virus. For instance in Kerala state of India, the dispersed settlement patterns played an important role as against the nucleated, semi-compact or compact patterns elsewhere in the country including the West. This made the home quarantine and isolation easier than in other places. Kerala could control the infection initially and this was hailed by WHO as 'learnings' [3]. It was mentioned that early screening, isolation of high-risk contacts, risk communication and community engagement etc. were responsible for this. Although not considered extraordinary, some scholars consider this possible because management and control received the highest political and administrative commitment with proactive timely interventions [4]. The importance of surveillance, good quality quarantine, testing strategies, uninterrupted treatment services, community participation, proactive care of elderly and people with comorbidity and educational and social mobilisation of behavioural change etc. have been pointed out as factors which contributed to effective management and control of COVID-19 in Kerala. In other words, mainly public health oriented control measures were solely held responsible for the so-called success in Kerala. But such optimism did not last long and the virus had an upper hand despite all these claims and presently the Kerala state is experiencing a drift towards a different scenario. After the one single case on 30 January, it soon hit the peak with super spread and community spread reported in some areas (Figure 1). The number of cases reported as on 30 July is 22303 plus 506 [5]. The Indian scenario is considerably diverse with a few states such as Maharashtra, Tamil Nadu, Delhi, Andhra Pradesh etc. experiencing the peak. The state of Maharashtra recorded the highest number of cases $(3,83,723)$ and highest number of deaths $(13,883)$ followed by the state of Tamil Nadu $(2,20,716$ cases and 3571 deaths). It appears that these trends are likely to continue for some more time. Given the diversity, the trends in India cannot be compared to the pandemic experience in other countries. But given the limitations in our knowledge regarding the virus behaviour, the country experiences or the micro experiences of states within countries could be useful for evolving appropriate control strategies. It is in this context that Turkey scenario could be useful (Figures $2 \& 3$ ). 


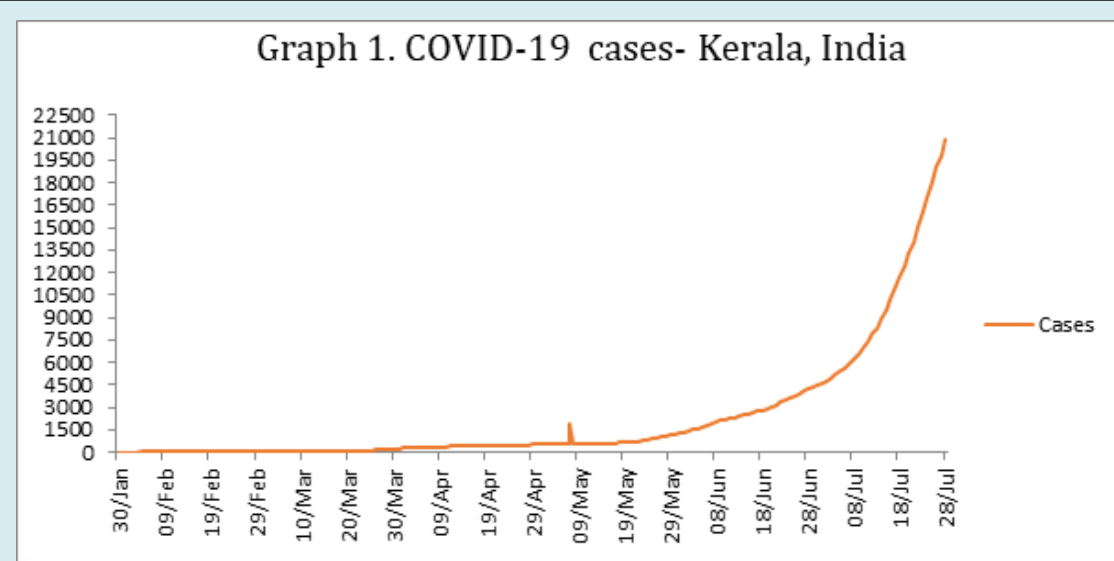

Source: https://dashboard.kerala.gov.in

Figure1: Covid-19 cases-Kerala, India.
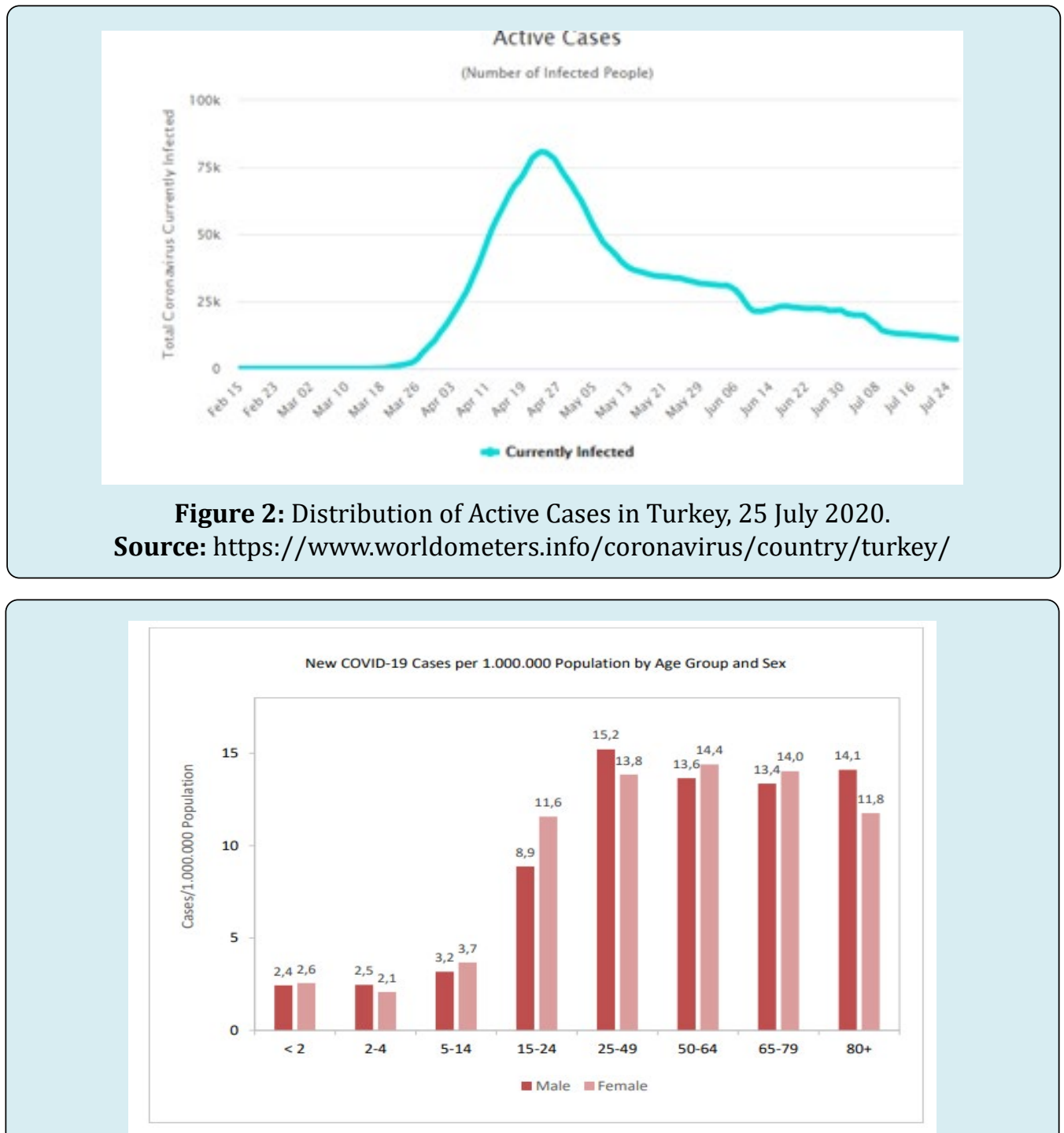

Figure 3: Distribution of New Covid-19 cases by Age Group and Gender (July 25, 2020). 


\section{COVID-19 in Turkey}

The COVID-19 pandemic has inflicted considerable suffering and death among the population in Turkey especially the initial surge in several provinces along the South Eastern part of Turkey nearby to the Middle East Area and Istanbul (Figure 4). The 7-day incidence with more than new 15 cases per 100.000 populations was observed in only south eastern Anatolia Region. Mardin, Gaziantep, Diyarbakır, and Konya have the highest incidence rate among metropolises. Compared to the previous day, the number of new COVID-19 cases, and the number of new hospitalizations decreased (respectively $-1.8 \%$ and $-1.5 \%$ ). The number of new COVID-19 cases per 1.000.000 population was 1.8 for women and 15.2 for men among the 25-49 age groups. North Eastern Anatolia, Western Black sea, Eastern Marmara, Western Anatolia, Eastern Black sea, and Aegean Regions witnessed a drop in the proportion of new hospitalizations (respectively $-62.5 \%,-53.8 \%,-26.0 \%-21.7 \%,-7.7 \%$ and, $-5.3 \%)$. On the other hand, the South Eastern Anatolia Region has the highest increase in the percentage change of the number of new hospital discharges compared to the previous day $(71.2 \%)$.

Turkey is one of the few countries in the world which effectively handled the COVID-19 virus largely due to a scientific approach with rigorous testing. After the first COVID-19 cases in Turkey were notified on 11 March 2020, $4,572,688$ tests were performed in total [6] and test per 1 million population is found to be 54,178 (Table 1b.) In total, 226,100 laboratory-confirmed COVID-19 cases and 5,613 deaths due to COVID-19 have been reported in Turkey (Table 1a-b). Total number of hospitalizations was 119717 and 3707 patient were hospitalized between 13-20 July 2020. Recovery rate and death rate of all confirmed cases were $86.04 \%$ and $2.57 \%$ respectively. What is observed regarding the number of active cases in Turkey is a peak sometime around the middle of April and then a gradual flattening (Figure 2). Of all the reported cases, $48 \%$ were female and $52 \%$ were male. The age distribution of reported cases Among all those notified cases, 15916 were children under 15 years of age (7.2\%), 30513 persons aged 15 to 24 years (13.8\%), 109086 persons aged 25 to 49 years (49.4\%), 40867 persons aged 50 to 64 years $(18.5 \%), 18594$ persons aged 65 to 79 years (8.4\%) and 5681 persons aged 80 years and older $(2.6 \%)$. The age is unknown for 1 notified case.

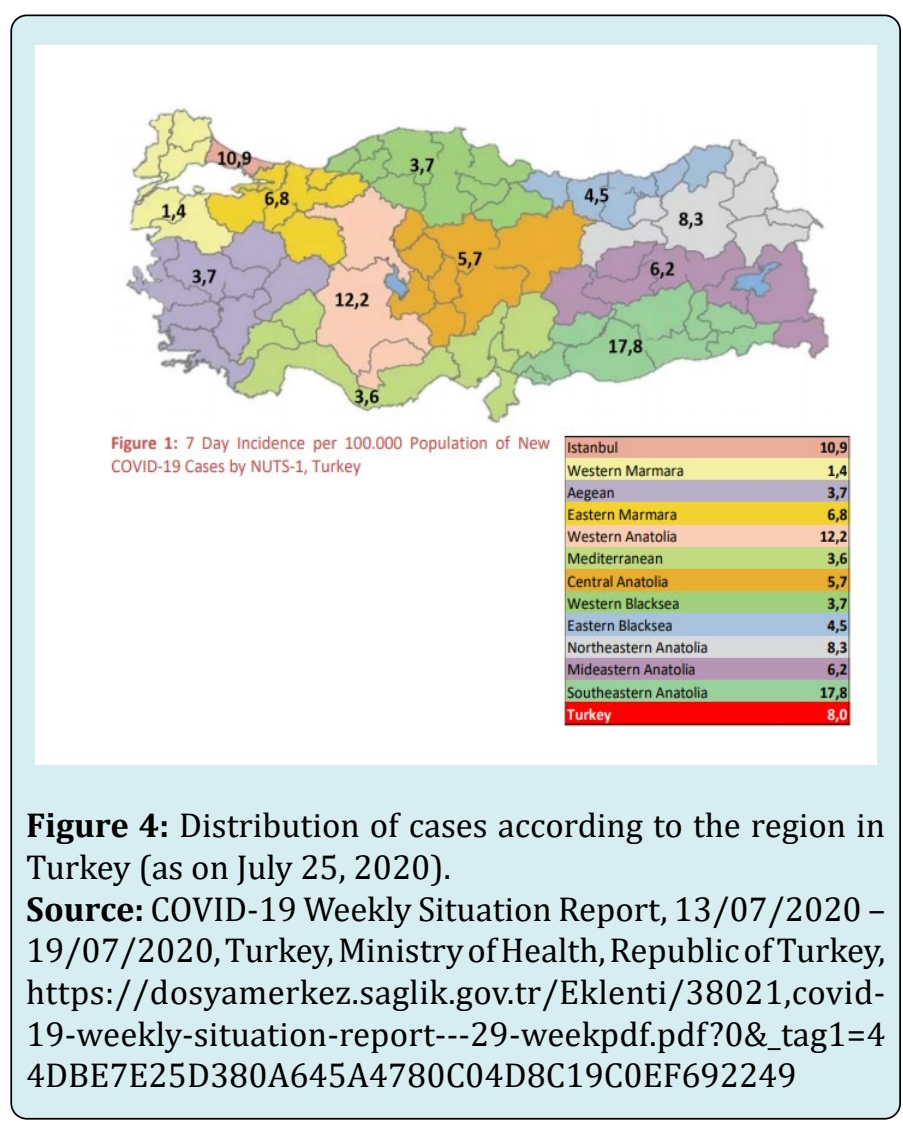

\begin{tabular}{|c|c|c|c|c|}
\hline Indicator & Total & $\begin{array}{c}\text { Total* Last 7 } \\
\text { Days** }\end{array}$ & $\begin{array}{c}\text { Difference Between } \\
\text { Previous Week }\end{array}$ & $\begin{array}{c}\text { Change From Previous } \\
\text { Week, (\%) }\end{array}$ \\
\hline \#of Tests & 4292045 & $297935-$ & -47080 & -13.6 \\
\hline \#of Cases & 220658 & 6629 & -553 & -7.7 \\
\hline \#of Deaths & 5491 & 128 & -10 & -7.2 \\
\hline \#of Hospitalization & 119717 & 3707 & -1965 & -34.6 \\
\hline \#of Intubated Patient & 8.8 & 311 & -36 & -10.4 \\
\hline $\begin{array}{c}\text { \#of Discharged From } \\
\text { Hospitals }\end{array}$ & 118087 & 3682 & -3881 & 51.3 \\
\hline
\end{tabular}

Table 1a: COVID-19 Distribution of Lab-confirmed Cases: Turkey (As of 25 July 2020).

Source: COVID-19 Situation Report Turkey, Ministry of Health, Republic of Turkey, 30/06/2020, world https://www. worldometers.info/coronavirus/ 


\begin{tabular}{|c|c|}
\hline Indicators & Per 1 Million Population \\
\hline Total Cases & 2,679 \\
\hline Deaths & 67 \\
\hline Test/1M Pop & 54178 \\
\hline Total Test & $45,72,688$ \\
\hline Population & $8,44,01,071$ \\
\hline
\end{tabular}

Table 1b: COVID-19 Distribution of Lab-confirmed Cases, Turkey (As of 25 July 2020).

Source: https://www.worldometers.info/coronavirus/, 27 July, 2020.

Source: COVID-19 Weekly Situation Report, 13/07/202019/07/2020, Turkey, Ministry of Health, Republic of Turkey, https://dosyamerkez.saglik.gov.tr/Eklenti/38021,covid-19weekly-situation-report---29-weekpdf.pdf?0\&_tag1=44DBE 7E25D380A645A4780C04D8C19C0EF692249.

The number of new COVID-19 cases per 1.000.000 population was 13.8 for women and 15.2 for men among the 25-49 age groups (Figures 3). The age distribution of the cases shows that the adult population above the age of 25 years were the most affected. The highest incidences were seen in persons aged 80 years and older while the highest 7-day incidences per 100.000 populations of new COVID-19 cases were seen in the 25-49 age groups.

As seen in Map 1, the highest incidence rate is determined at South-eastern Anatolia (178/100000) followed by Western Anatolia l with a rate of $1122 / 100000$. Considering the percentage of changes in the cases by NUTS-1, the highest decrease was in the Western Black sea Region (-41.7\%), the highest increase was in Central Anatolia Region (51.7\%) compared to the previous day. When analysed in terms of the number of cases, this difference was only 9 cases. (As on July $26,2020)$.

\section{Deaths}

In total, 5.491 COVID-19 related deaths have been reported and confirmed by the Ministry of Health in Turkey. Death rate of all confirmed cases was $2.49 \%$ and deaths per 1 million population is 67 as of July 25, 2020 (Table 1b). The lowest death rates were $0.03 \%$ for aged $2-4$, and $15-24$, and the highest death rate was $26,54 \%$ for patients aged 80 and older (Table 2).

\begin{tabular}{|c|c|c|c|c|c|c|c|c|}
\hline Death Rate & $<\mathbf{2}$ & $\mathbf{4 - F e b}$ & $\mathbf{1 4 - M a y}$ & $\mathbf{1 5 - 2 4}$ & $\mathbf{2 5 - 4 9}$ & $\mathbf{5 0 - 6 4}$ & $\mathbf{6 5 - 7 9}$ & $\mathbf{8 0 +}$ \\
\hline Male & 0.34 & 0.06 & 0.04 & 0.01 & 0.42 & 4.26 & 16.79 & 32.03 \\
\hline Female & 0.27 & 0 & 0.05 & 0.04 & 0.21 & 1.75 & 8.96 & 22.61 \\
\hline Total & 0.31 & 0.03 & 0.04 & 0.03 & 0.32 & 3.06 & 12.7 & 26.54 \\
\hline
\end{tabular}

Table 2: Death Rate of Confirmed Cases by Age Group and Gender (\%), Turkey.

Source: COVID-19 Weekly Situation Report, 13/07/2020 - 19/07/2020, Turkey, Ministry of Health, Republic of Turkey, https:// dosyamerkez.saglik.gov.tr/Eklenti/38021,covid-19-weekly-situation-report---29-weekpdf.pdf?0\&_tag1=44DBE7E25D380A64 5A4780C04D8C19C0EF692249

The highest number of deaths per 100.000 populations was recorded in Istanbul (17.7) Eastern Marmara (6.9) Western Anatolia and South-eastern Anatolia (5.0) while lowest number of deaths per 100.000 populations was 1.3 , 1.6 and 2.2 respectively for Mediterranean, Mid-eastern Anatolia and Central Anatolia regions. As for hospital care, as of $19 / 07 / 2020$, the number of new hospitalizations was 119,717 . The percentage of hospitalizations was $54.3 \%$ among all COVID-19 cases. 7.4\% of all hospitalized patients were intubated and $98.6 \%$ were discharged from hospital.

\section{How did Turkey control the virus?}

It is possible that the data reported here may not reflect the true picture but with whatever limitations in the data, it is possible to say that the country achieved some success in controlling the virus. We do not want to present this as a model as it is now known that there is no model for the COVID-19 virus control. There is no uniformity with respect to the virus behaviour in many countries. This could be largely due to the contexts especially the ecological and demographic features. Like many tentative assumptions surrounding the virus- preventive strategies, treatment etc., it appears that the present virus has a larger ecological sensitivity. As earlier mentioned, it may be biologically wrong to assume that ecology does not influence the virulence of a fundamental cell structure like virus which exist 'on borrowed life' (as Virologists Marc H. V. van Regenmortel of the University of Strasbourg in France and Brian W. J. Mahy of the Centre's for Disease Control and Prevention have described them). But in this case, the human sensitivity based on ecology may also be present. Unlike the earlier pandemics, this episode also needs scrutiny from that angle. This is important to assess the role of different preventive measures in containing the spread. Especially this is important given the fact that the home-based confinement, lockdown of offices, factories etc., physical distancing, universal use of masks etc. in such an epidemic needs scientific assessment from public health, 
epidemiologic and virologists angle. The success in Turkey could also be attributed to strict enforcement of Standard protocols. Some scholars consider that the flattening of the curve in Turkey is an evidence of the effectiveness of control measures [7]. The country restricted the entry of non-Turkish travellers from any other parts of the world for a period of 14 days during the period from March 11 to June 1. Like many other countries, strict quarantine was also enforced. Turks coming from abroad were quarantined at guest houses for 14 days (for those with no clinical signs), and at designated hospitals in each province (for those with clinical symptoms) till June 1 . In addition, the usual standard protocols were also followed such as restrictions on meetings, gatherings and travel. The country also adopted a fast track mechanism to procure medical supplies, test kits, PPEs, thermal scanners, and other needed diagnostic and curative commodities and distribute it to all possible sites (Ports of Entry, Government buildings, etc.) $[8,9]$.

\section{Conclusion}

The coronavirus COVID-19 pandemic is the defining global health crisis of our time and the greatest challenge we have faced since World War Two. Since its emergence in Asia late last year, the virus has spread to every continent except Antarctica. The pandemic is much more than a health crisis and it is also an unprecedented socio-economic crisis. There is no doubt that the pandemic has already led to devastating social, economic and political effects that will leave deep and longstanding scars. In some countries and regions, the cases are still rising while in others such as Turkey, the infection rate is declining with some sporadic cases with many countries and regions slowly opening to greater human interaction. The two cases presented here show that it is too early to jump into conclusions regarding success or failures in control measures. There are still many unknown entities regarding the behaviour of the virus.

However, presentation of case studies would help in finding ways to manage similar pandemics and outbreaks in future. In the longer term, we should look at ways to better prevent and manage such crises and ensure that the world makes full use of what we will learn from this one. This is the reason why there is a need to examine country case studies to understand patterns especially similarities and differences. Unfortunately, some countries have limited data accessibility in the name of ethical issues. But an on-going epidemiological assessment based on data is extremely important to strengthen the fight against the pandemic. This is extremely useful for developing an integrated global response as an investment for our future.

\section{References}

1. Morens DM, Taubenberger JK, Harvey HA, Memoli MJ (2010) The 1918 Influenza Pandemic: Lessons for 2009 and the Future. Crit Care Med 38(4): 1-21.

2. https://www.who.int/news-room/fact-sheets/detail/ west-nile-virus

3. https://www.who.int/india/news/feature-stories/ detail/responding-to-covid-19---learnings-from-kerala

4. Menon JC, Rakesh PS, John D, Rajesh T, Banerjee A (2020) What was right about Kerala's response to the COVID-19 pandemic? BMJ Global Health 5(7): 1-5.

5. https://dashboard.kerala.gov.in

6. https://www.worldometers.info/coronavirus/country/ turkey/

7. Cakir B (2020) COVID-19 in Turkey: Lessons learned. Journal of Epidemiology and Global Health 10(2): 115117.

8. (2020) COVID-19 Weekly Situation, Turkey, Republic of Turkey, Ministry of Health.

9. (2020) COVID-19 Daily Situation, Republic of Turkey, Ministry of Health. 